\title{
Bilateral Ablation of Auditory Cortex in Mongolian Gerbil Affects Discrimination of Frequency Modulated Tones but not of Pure Tones
}

\author{
Frank W. Ohl, ${ }^{1}$ Wolfram Wetzel, Thomas Wagner, Alexander Rech, \\ and Henning Scheich \\ Leibniz Institute for Neurobiology (IfN) \\ D-39118 Magdeburg, Germany
}

\begin{abstract}
This study examines the role of auditory cortex in the Mongolian gerbil in differential conditioning to pure tones and to linearly frequency-modulated (FM) tones by analyzing the effects of bilateral auditory cortex ablation. Learning behavior and performance were studied in a GO/NO-GO task aiming at avoidance of a mild foot shock by crossing a hurdle in a two-way shuttle box. Hurdle crossing as the conditioned response to the reinforced stimulus $(\mathrm{CR}+)$, as false alarm in response to the unreinforced stimulus (CR-), intertrial activity, and reaction times were monitored. The analysis revealed no effects of lesion on pure tone discrimination but impairment of FM tone discrimination. In the latter case lesion effects were dependent on timing of lesion relative to FM tone discrimination training. Lesions before training in naive animals led to a reduced $\mathrm{CR}+$ rate and had no effect on CR- rate. Lesions in pretrained animals led to an increased $C R$ - rate without effects on the $\mathrm{CR}+$ rate. The results suggest that auditory cortex plays a more critical role in discrimination of FM tones than in discrimination of pure tones. The different lesion effects on FM tone discrimination before and after training are compatible with both the hypothesis of a purely sensory deficit in FM tone processing and the hypothesis of a differential involvement
\end{abstract}

\footnotetext{
${ }^{1}$ Corresponding author.
}

of auditory cortex in acquisition and retention, respectively.

\section{Introduction}

The auditory cortex of mammals is believed to be the substrate for particular aspects of auditory stimulus processing, to mediate certain forms of auditory performance, as well as to play a role in auditory learning (e.g., Aitkin 1990; Scheich 1991; Recanzone et al. 1993; Ehret 1997; Scheich et al. 1997). Past studies have revealed large species differences in the involvement of auditory cortex (e.g., Bullock 1997). Moreover, for a given species, the relevance of auditory cortex seems to be dependent on the complexity of auditory signals as well as details of the training paradigm. Hence, the current state of research does not yet allow broader generalizations about the role of auditory cortex in stimulus processing and learning independent of species, stimuli, and task (e.g., Thompson 1983, 1997; Bullock 1997; Heffner 1997). It is therefore necessary to determine the relevance of auditory cortex in important learning and performance paradigms for selected species. The present study examines the role of auditory cortex in the Mongolian gerbil (Meriones unguiculatus) for behavioral discriminations between pure tones and between frequency-modulated (FM) tones in a differential conditioning paradigm. The remaining part of the introduction motivates the details of the present experimental approach.

The Mongolian gerbil, a small desert rodent, was chosen because it has become an important model system in research on auditory physiology and plasticity and possesses a well-investigated auditory cortex (for review, see Scheich 1991). It was suited for the present study because the functional

LEARNING \& MEMORY 6:347-362 @ 1999 by Cold Spring Harbor Laboratory Press ISSN1072-0502/99 \$5.00

$$
\begin{array}{lllllllllllllll}
L & E & A & R & N & I & N & G & \underset{347}{\mathbf{Z}} & M & E & M & O & R & Y
\end{array}
$$


organization of the gerbil auditory cortex was characterized not only using pure tones (Ryan et al. 1982, 1989; Scheich et al. 1993a; Thomas et al. 1993; Hess and Scheich 1996; Sugimoto et al. 1997), but also using complex and FM tones (Zuschratter et al. 1995; Ohl and Scheich 1997b; Schulze et al. 1997). Moreover, physiological correlates of learning-related changes have been demonstrated in the gerbil auditory cortex: Using metabolic labeling techniques large-scale learning-induced alterations of neuronal activity patterns were found by Scheich et al. (1993b, 1997). The study by Cahill et al. (1996) revealed a redistribution of metabolic labeling from primary auditory cortex to secondary fields after cross-modal lighttone conditioning. Using single- and multi-unit electrophysiology our earlier studies have demonstrated that the receptive fields of single units in gerbil auditory cortex show frequency-specific plasticity to pure-tone conditioning (Ohl and Scheich 1996). Such neuronal plasticity might provide a potential substrate for auditory learning. The recently demonstrated learning-induced modulation of the fast (millisecond) time courses of neuronal responses in gerbil auditory cortex (Ohl and Scheich 1997a) seems especially suited for coding newly learned information associated with FM sounds. Despite the abundance of physiological data on stimulus processing and learning-related plasticity in the gerbil auditory cortex, its relevance for stimulus processing in the corresponding paradigms has, as it is the case for most species in auditory research, remained speculatory. It has been noted that the imbalance between data on functional auditory cortical organization and data on functional relevance is especially severe for rodents (M.G. Clark, Y.H. Liu, T.M. Perney, P. Tallal, and R.H. Fitch, unpubl.). The present study aims to take advantage of a well-investigated model species to obtain further insight in the functional relevance of rodent auditory cortex.

With respect to acoustic stimuli we focused on FM tones because they form an important class of stimuli and of stimulus components. FM segments are abundant in communication sounds of most mammals (e.g., Collias and Joos 1953; Winter 1966; Suga 1968; Brown et al. 1978; Newman 1978; Esser and Lud 1997) including the gerbil (Holman and Seale 1991; Setzer 1992; Yapa 1994). Also, FM elements occur as perceptually relevant transients in human speech sounds (e.g., Liberman and Studdert-Kennedy 1978; Bailey 1979; Fitch et al. 1997) where they can serve as discriminators between consonant-vowel syllables, and it has been suggested that certain forms of developmental dysphasias are due to a disturbed processing of FM sounds (Stefanatos et al. 1989). Selectivity to FM parameters such as direction of modulation or rate of change of frequency is generally reported to increase from peripheral to central stations of the auditory pathway (e.g., Whitfield 1969; Kelly and Whitfield 1971; Phillips et al. 1991). In the gerbil auditory cortex several types of neuronal response patterns to FM tones have recently been described (Schulze et al. 1997). The electrophysiological study by Schulze et al. (1997) revealed the existence of several different response types of units distributed over separate regions of auditory cortex indicating cortical specializations for the analysis and representation of gross temporal response properties. Therefore, FM tones appear to be a suitable stimulus class to examine auditory cortex relevance especially if lesion effects on FM tone processing can be compared to effects on processing of pure tones, which lack the spectral and temporal complexity of the former.

For the behavioral analysis we used a shockavoidance GO/NO-GO training procedure in a differential conditioning paradigm to obtain measures for conditioned reactions to both the reinforced stimulus $(\mathrm{CR}+)$ and reactions to the unreinforced stimulus (CR-). This paradigm has recently been used to describe FM tone-discrimination behavior and concept transfer in gerbils (Wetzel et al. 1998). Whereas most of the previous studies investigating lesion effects on performance in auditory learning tasks had utilized either classical conditioning paradigms or detection tasks often requiring the detection of only a change in stimulus conditions, more recent studies suggested different mechanisms of auditory cortex for mediating CR+ and CR-, respectively (e.g., Jarrell et al. 1987; Teich et al. 1988), making separate record of both behaviors desirable.

We chose the lesion method, specifically the total ablation of auditory cortex, to supplement previous findings from recording experiments invoking FM stimuli (Schulze et al. 1997). Recording experiments can demonstrate the sensitivity of neuronal systems to the considered stimulus classes but are unable to illuminate the relevance of such systems for processing of stimuli. Although impairment of processing after lesion does not allow the conclusion that the structure is essential for the function (e.g., Grobstein 1990), it can be concluded that at least the structure is typically

$$
\begin{array}{llllllllllllllll}
L & E & A & R & N & I & N & G & \underset{348}{\mathbf{Z}} & M & E & M & O & R & Y
\end{array}
$$


involved in processing these stimuli in the context of the behavioral task studied. To assess the relevance of gerbil auditory cortex in FM tone discrimination it is therefore necessary to study conditioning and performance after eliminating auditory cortical contribution.

\section{Materials and Methods}

\section{ANIMALS}

Thirty-one male, 3- to 6-month-old Mongolian gerbils (M. unguiculatus) weighing 65-110 grams were obtained from a commercial distributor (Mollegard, Denmark) and housed in a temperaturecontrolled room $\left(23 \pm 1{ }^{\circ} \mathrm{C}\right)$ under $12 \mathrm{hr}$ light/12 hr dark cycle (light on 06:00-18:00 hr). Animals had free access to water and food (rodent food pellets and sunflower seeds) and received vegetables on an occasional basis.

\section{APPARATUS AND TRAINING PROCEDURE}

Animals were trained in a two-compartment shuttle box (E10-E15, Coulbourn Instruments) using a GO/NO-GO discrimination procedure. The compartments $(18 \times 16 \times 22 \mathrm{~cm})$ were separated by a 3 -cm-high hurdle. Mild electrical foot shocks (100-600 $\mu \mathrm{A})$ applied through the floor grid served as unconditioned stimuli (US). Training was carried out in daily sessions consisting of 60 trials each, that is, 30 presentations of the US-reinforced conditioned stimulus (CS+) and 30 presentations of the unreinforced conditioned stimulus (CS-) presented in randomized order after fixed intertrial intervals of $15 \mathrm{sec}$. Each trial started with the presentation of a CS. After $4 \mathrm{sec}$ the CS+ presentation was followed by a US unless the animal had crossed the hurdle during $\mathrm{CS}+$ presentation, which would terminate CS+ presentation and trial and be counted as a $\mathrm{CR}+$, that is, conditioned reaction toward the CS+. The US lasted for up to $4 \mathrm{sec}$ and could be terminated by the animal by crossing the hurdle. If the animal crossed the hurdle after presentation of the CS-, it was counted as a false alarm, CR-, that is, conditioned reaction towards the CS-. Occurrences and times of hurdle crossings were monitored by a computer program.

The CS stimuli consisted of a 4-sec pure tone (CS+: $0.5 \mathrm{kHz}$; CS-: $4.0 \mathrm{kHz}$ ) in one experimental group (experiment A) and sequences (0.25-sec CS followed by 0.25 -sec pause) of linear FM tones (CS+: sweeping from $0.5 \mathrm{kHz}$ to $4.0 \mathrm{kHz}$; CS-: sweeping from $4.0 \mathrm{kHz}$ to $0.5 \mathrm{kHz}$ ) in two other experimental groups (experiments B and C). All stimuli were digitally synthesized $(44.1-\mathrm{kHz}$ sampling rate, 16-bit dynamic range) with $5 \mathrm{msec}$ rise/ decay times to reduce spectral splatter and presented after digital-to-analog conversion using a commercial computer sound card from a loudspeaker mounted in the middle of the shuttle box roof at moderate levels of $65-$ to $70-\mathrm{dB}$ sound pressure level (as measured by a Brüel \& Kjaer 2610 sound level meter connected to a Brüel \& Kjaer 4134 condenser microphone located at various positions in the shuttle box compartments at the approximate position of the animal's head).

\section{ANALYSIS OF BEHAVIORAL DATA}

Two basic behaviors were monitored as CRs: GO (hurdle crossing) and NO-GO behaviors. GO responses were classified as correct responses or hits (CR+, i.e., CR elicited by the CS+) or false alarms (CR-, i.e., CR elicited by the CS-). CR+ rates, $\mathrm{CR}-$ rates, intertrial crossing rates (hurdle crossings occurring in the intertrial interval) as well as mean crossing times (times between stimulus onset and hurdle crossing) were calculated from the stored data for each animal and session. Rates were expressed as relative frequencies by dividing the count of behaviors by the number of trials. Discrimination performance was quantified by the measure $D=(\mathrm{CR}+$ rate $)-(\mathrm{CR}-$ rate $)$ and tested using the Wilcoxon test on a significance level of $P<0.05$ against the null hypothesis of equal CR+ and CR- frequencies of occurrence. Group means and standard errors of mean (s.E.M.) were calculated from individual $\mathrm{CR}+$ and $\mathrm{CR}-$ rates as well as for individual mean crossing times. Differences in mean performance and in mean crossing times between lesioned and control groups were tested by the Mann-Whitney $U$ test on a significance level of $P<0.05$ against the null hypothesis of equal performance and crossing times, respectively. The significance level was chosen to facilitate comparison of results between different experiments in this study and with published data (Wetzel et al. 1998). In experiment A, additional testing of discrimination performance on single sessions and single animals was performed by submitting a fourfold table, constructed from the four combinations of $\mathrm{CR}+$ and $\mathrm{CR}-$ as responses to CS+ and CS- stimuli, to a $\chi^{2}$ test. Differences in learning performance between animals of experiment $B$ and preoperative performance of lesioned and

$$
\begin{array}{lllllllllllllll}
L & E & A & R & N & I & N & G & \begin{array}{l}
\boldsymbol{Q} \\
\mathbf{3 4 9}
\end{array} & M & E & M & O & R & Y
\end{array}
$$


sham-lesioned animals in experiment $C$ were tested using the Kruskal-Wallis $\mathrm{H}$ test on a significance level of $P<0.05$. On the data from one animal in experiment C Dixon's outlier test was performed on the differences between mean preoperative discrimination performance ( $D$ values averaged over the last four sessions preceding the operation) and mean postoperative discrimination performance ( $D$ values averaged over all sessions after the operation) on a significance level of $P<0.05$.

\section{LESION PROCEDURE}

Auditory cortex lesions and sham-lesions were performed under deep ketamine anesthesia (xylazine, $2 \mathrm{mg} / 100$-gram body weight, i.p.; ketamine, $20 \mathrm{mg} / 100$-gram body weight, i.p.). Bilateral auditory cortex lesions were executed by thermocoagulation of auditory cortex after skin removal and drilling of a hole ( $4 \mathrm{~mm}$ diam.) into the skull over the temporal cortex. The cylindrical coagulator was moved through the skull opening tangentially over the most lateral convexity of the temporal cortex in a dorsoventral fashion (Fig. 1A, left) ensuring correct localization and completeness of lesion (Fig. 1B). After thermocoagulation the skin was closed over the trepanation area and sealed with tissue glue. Animals were treated with a local anesthetic (10\% lidocaine spray) and local application of antibiotics ( $0.25 \%$ neomycin paste). Shamlesioned gerbils were operated on the same manner except for the thermocoagulation. All animals were given 2-5 days for recovery after the operation.

\section{HISTOMETRIC ANALYSIS OF LESIONS}

Localization of lesion was verified and extent determined after completion of behavioral experiments using 2-fluoro-2-deoxy-D-[ $\left.{ }^{14} \mathrm{C}(\mathrm{U})\right]$ glucose (FDG) autoradiography of serial horizontal brain sections (Fig. 1, A, right, and $\mathrm{B}$ ). In addition to the anatomical verification to which classical methods are restricted this method allows assessment of the functional effectiveness of the lesion by investigating metabolic labeling. Compared to more classical techniques this method is additionally suited for our purpose because of the minimal stereometric distortion due to the dispensability of histological fixation techniques. The method has been detailed elsewhere (Scheich et al. 1993a). In short, animals were injected i.p. with $18 \mu \mathrm{Ci}$ of radioactively labeled FDG and exposed to a 45-min stimulation with repeated test pulses $(0.5$-sec pure tone, $1 \mathrm{kHz}$ at $60-75 \mathrm{~dB}$ SPL followed by 0.5 -sec silence) in a sound-attenuated illuminated chamber. This configuration labels all fields of the auditory cortex with a peak of labeling along the $1-\mathrm{kHz}$ isofrequency contours in all fields (Scheich et al. 1993a) and also allows identification of the neighboring somatosensory and visual cortices. Autoradiographs were obtained from $40-\mu \mathrm{m}$ serial horizontal sections. Autoradiographs of every other second section were optically magnified $(8 x)$, recorded by a CCD camera, and digitized for computerized histometric analysis using the NIH-image system yielding a $80-\mu \mathrm{m}$ resolution for the histometric analysis in the dorsoventral direction. In each recorded horizontal section the area of the lesion site was determined and the corresponding volume was determined by multiplying by $80 \mu \mathrm{m}$.

\section{Results}

Three experiments were conducted in this study: Experiments A and B studied the effects of bilateral auditory cortex lesion on the acquisition of pure tone discrimination and FM tone discrimination, respectively, in a foot shock-motivated GO/ NO-GO paradigm. Effects produced by the lesion were found only in experiment $B$ and subsequently compared with lesion effects on retention in animals previously trained to discriminate FM tones (experiment C). After completion of behavioral experiments size and locus of lesion were examined using FDG autoradiography. The following report includes only those animals in which lesion covered but did not exceed the entire auditory cortex as defined by functional FDG mapping (Scheich et al. 1993a).

\section{LESIONS}

Position and spatial extent of the bilateral auditory cortical lesions were determined using FDG autoradiography (see Materials and Methods) to enhance detection of possible functional cortical activity remaining after the lesion. Figure 1A shows a schematic diagram of the lesion procedure (left panel) and an autoradiograph from a horizontal section through the brain of a control gerbil illustrating the position of the auditory cortex after stimulation with a $1-\mathrm{kHz}$ test tone (right panel). In the autoradiograph such a test stimulus produces

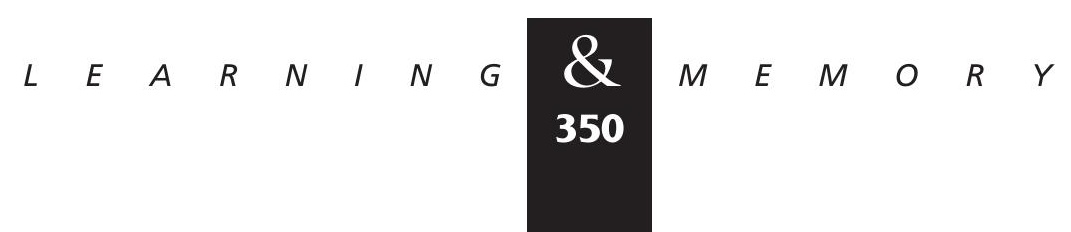



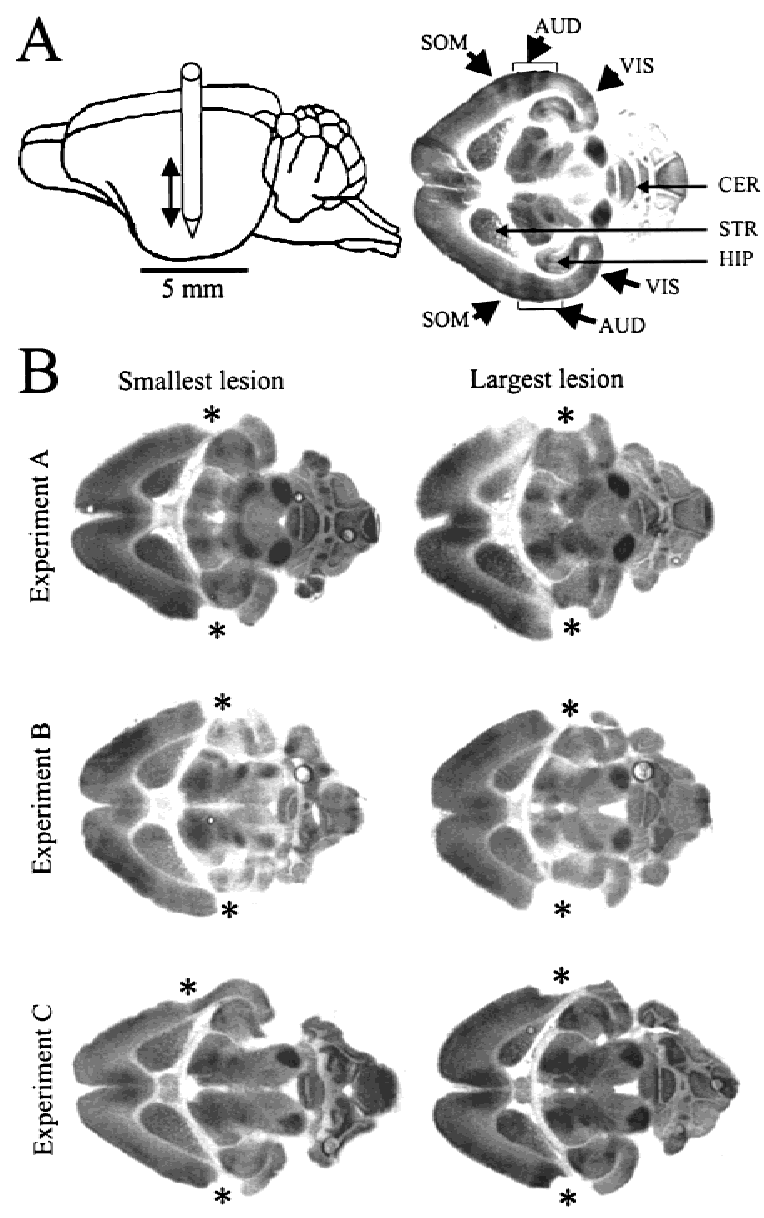

radial bands of metabolic labeling in the auditory cortex. Although these bands reach their highest optical density in the region of the tonotopic representation of the test stimulus frequency they allow in their entirety the localization and determination of spatial extent of the auditory cortex (Scheich et al. 1993a). Two radial stripes, corresponding to the two auditory cortical core fields AI and AAF, are visible at rostrocaudal positions centered around the anterior tip of the hippocampus. Often, somatosensory and visual cortical activity can also be seen as radial bands in the autoradiographs of horizontal sections marking the location of these cortices.

The autoradiographic analysis of serial horizontal brain sections revealed that the described lesion method allowed a relatively precise ablation of auditory cortex with no obvious sign of interference with functional activity in somatosensory and visual cortical areas and subcortical structures. Figure 1B shows the smallest and largest lesions produced in each of the experimental groups. In all
Figure 1: $(A)$ (Left) Schematic diagram of lesion procedure. Position and dorsoventral movement of the thermocoagulator are displayed relative to a gerbil brain. (Right) Autoradiograph of horizontal section through a gerbil brain. Dark areas in the autoradiographs indicate increased metabolic activity. In the cortex, metabolic labeling is apparent as radial stripes in somatosensory cortex, auditory cortex, and visual cortex. Note in auditory cortex two dark bands in the auditory cortex, corresponding to fields $\mathrm{Al}$ and $\mathrm{AAF}$, as the characteristic activation pattern produced by a $1-\mathrm{kHz}$ pure tone test stimulus presented at 60-75 dB SPL (see Materials and Methods) for precise localization of the auditory cortex on the most lateral convexity of the temporal cortex. (AUD) Auditory cortex; (CER) cerebellum; (HIP) hippocampus; (SOM) somatosensory cortex; (STR) corpus striatum; (VIS) visual cortex. (B) Autoradiographs of horizontal brain sections displaying the smallest and the largest lesions produced in experiments $\mathrm{A}, \mathrm{B}$, and $\mathrm{C}$. Sections are oriented as in $A$, right; asterisks $(*)$ mark the bilateral auditory cortex lesion. Note the precision of lesion locus and absence of any remaining tone-evoked activity near the lesion site in all experiments as well as the small variability of lesion extent within and across experiments. Note in the smallest lesion in experiment $C$ a small rim of tissue that had remained after the operation in right temporal cortex but did not show any metabolic labeling.

groups position and spatial extent of lesions were similar to each other and the differences between smallest and largest lesions are relatively small in each group. In no case was functional auditory cortical activity detectable after the lesion nor did the lesion significantly extend the region of the auditory cortex. In the smallest lesion in experiment $\mathrm{C}$ a thin medial rim of cortical tissue remained after the lesion on the right side but did not show any traces of the high-contrast radially oriented stripes of tone-evoked metabolic activity. In two gerbils used in experiment $\mathrm{C}$ a thin rim of increased FDG labeling could be detected at the rostral border of the lesion, indicating either an artificially induced increased activity at the lesion site or a remaining trace of neural activity in field AAF due to an auditory cortex that was atypically far shifted into the rostral direction (for the variance of rostrocaudal position of field AAF, see Scheich et al. 1993a). Because the labeling trace did not indicate survival of an intact field these two gerbils were not excluded from the analysis. Figure 2 shows the

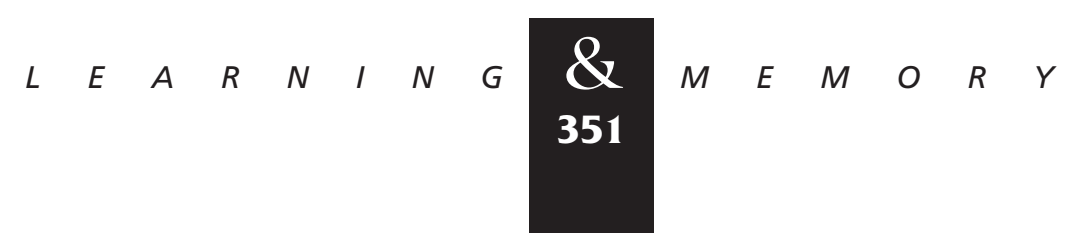




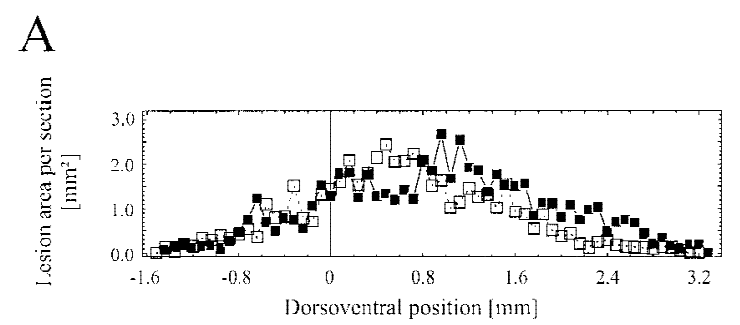

B

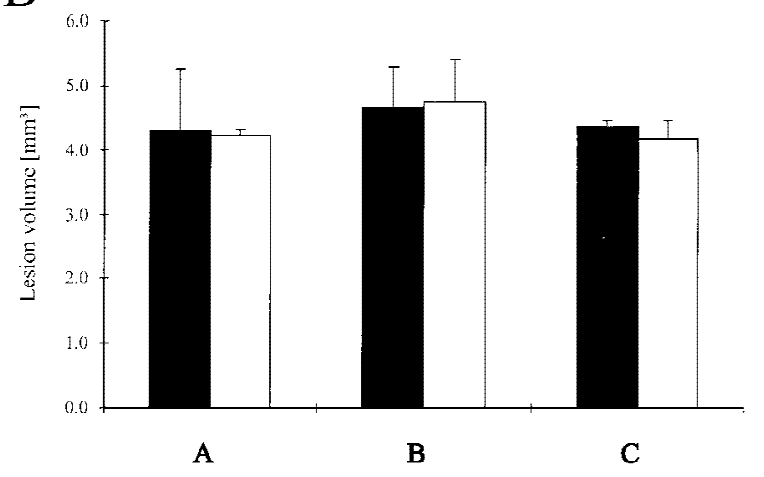

Figure 2: Histometric analysis of lesion volumes. (A) Representative example of lesion areas determined in serial horizontal brain sections of one gerbil along the dorsoventral direction for the left $(\boldsymbol{\square})$ and right $(\square)$ hemisphere. Positions along the dorsoventral direction were referenced to the dorsoventral position of the dorsal tip of the corpus striatum as a convenient anatomical landmark (Scheich et al. 1993a). (B) Comparison of mean lesion volumes in left (solid bars) and right hemispheres (open bars) for experiments A, B, and C. No statistical differences could be detected between these groups (Kruskal-Wallis, $P>0.1$ ).

results of a quantitative histometric analysis of the lesions based on measuring the lesion area in serial horizontal brain sections along the dorsoventral extent of the lesion with an $80-\mu \mathrm{m}$ resolution in that direction (Fig. 2A). Dorsoventral profiles of lesion area showed a maximum at dorsoventral positions between $0.5 \mathrm{~mm}$ and $1.0 \mathrm{~mm}$ ventral to the dorsal tip of the corpus striatum. This curvature reflects the intersection of the cylindrical track of the coagulator with the lateral convexity of the temporal cortex. Lesion volumes were calculated from these profiles and were found to be in the range from $4.2 \mathrm{~mm}^{3}$ to 4.8 $\mathrm{mm}^{3}$ in left and right auditory cortices for all three experiments (Fig. 2B). Mean lesion volumes were determined to $4.31 \pm 0.96 \mathrm{~mm}^{3}$ (left) and $4.22 \pm 0.10 \mathrm{~mm}^{3}$ (right) in experimental group A, $4.67 \pm 0.63 \mathrm{~mm}^{3}$ (left) and $4.76 \pm 0.64 \mathrm{~mm}^{3}$ (right) in experimental group B, and 4.36 $\left(0.08 \mathrm{~mm}^{3}\right.$ (left) and $4.17 \pm 0.27 \mathrm{~mm}^{3}$ (right) in experimental group C (Fig. 2B). There were no statistical differences between the six determined mean lesion volumes (Kruskal-Wallis, $P>0.1 ; \mathrm{H}=3.87<\chi_{\text {crit } ; \mathrm{df}=5 ; P \leq 0.1}^{2}=9.21$ ).

\section{EFFECTS OF LESION ON THE AQUISITION OF PURE TONE DISCRIMINATION (EXPERIMENT A)}

The effects of lesion on the acquisition of pure tone discrimination were studied using previously untrained animals receiving either auditory cortex lesion $(n=4)$ or sham-lesion $(n=4)$. Both groups were trained in daily sessions to discriminate a 0.5 $\mathrm{kHz}$ pure tone from a $4.0-\mathrm{kHz}$ pure tone. The group performances $D$ (differences between CR+ rate and $\mathrm{CR}$ - rate) of both the lesioned and control group reached significance (Wilcoxon, $P<0.075$; $\left.\mathrm{W}_{\text {crit. } ; n=4}=0\right)$ after session $4\left(\mathrm{~W}_{n=4}\right.$ for the eight sessions: $1.5,1.5 .2,0,0,0,0,0$ ), stabilizing at asymptotic levels of $60 \%$ (see Materials and Methods section for details on stimulus parameters, training paradigm, and data analysis). A small difference in group performance detectable on session 2 was not significant and was reflective of the fact that already in session 2 two animals of the control group had reached an individual $\chi^{2}$ statistic (see Materials and Methods) exceeding $\chi_{\text {crit;df }=1 ; P \leq 0.05}^{2}=3.84$. Group mean values of discrimination performance $D$ showed no significant differences (Fig. 3). In both groups the time

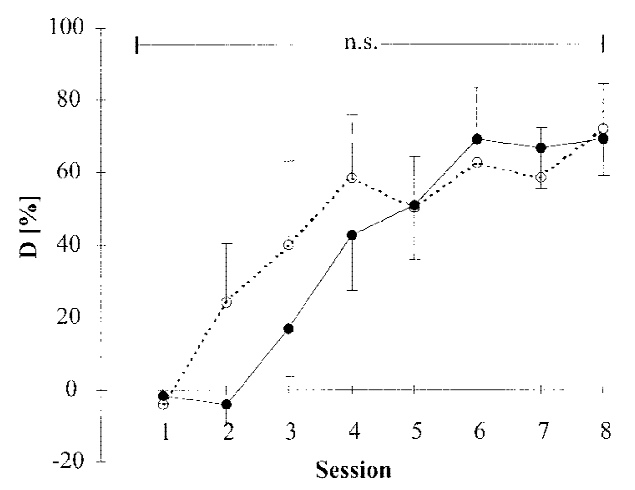

Figure 3: Time course of discrimination performance $D$ over 8 sessions of pure tone discrimination training after lesion (experiment A). Plotted are group mean values $(n=4)$ and standard errors of means (error bars point downward for lesion group and upward for control group). There were no significant differences between the experimental group (0) with bilateral lesion of the auditory cortex and the sham-lesioned control group $(\bigcirc)$. A weak but nonsignificant difference of discrimination performance was seen in session 2 .

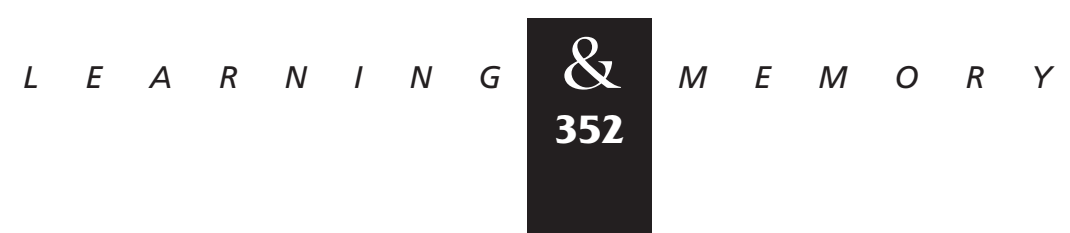


courses of $\mathrm{CR}+$ and $\mathrm{CR}$ - rate development as well as asymptotic performance level were similar to earlier observations of FM tone discrimination behavior (Wetzel et al. 1998). Mean crossing times gradually declined from $7.0 \pm 4.2 \mathrm{sec}$ in the first session to $2.5 \pm 1.2 \mathrm{sec}$ in the eighth session for the lesioned group and from $6.3 \pm 5.4 \mathrm{sec}$ to $2.8 \pm 1.0$ sec in the sham-lesioned group. There were no significant differences in $\mathrm{CR}+$ rate, $\mathrm{CR}-$ rate, and mean crossing times or intertrial activity between the lesioned and the control group either.

\section{EFFECTS OF LESION ON THE AQUISITION OF FM TONE DISCRIMINATION (EXPERIMENT B)}

The effects of lesion on the acquisition of FM tone discrimination were studied using a previously untrained group of animals. Animals received bilateral lesion of auditory cortex $(n=6)$ or shamlesion $(n=6)$ and were subsequently used in FM tone discrimination training. Sham-lesioned controls showed normal development of discrimination performance over trials yielding $>60 \%$ performance level and $>80 \% \mathrm{CR}+$ rate from session 6 on in accordance with earlier observations on the temporal development of performance in FM tone discrimination (Wetzel et al. 1998) and the temporal development observed for pure tone discrimination (experiment A). Auditory cortex lesioned animals showed a decreased rate of development and a reduced asymptotic level of discrimination performance $(D<40 \%)$. Significant (Mann-Whitney U, $P<0.05$, critical $\mathrm{U}$ values: $\mathrm{U}_{\mathrm{n} 1=\mathrm{n} 2=6 ; P \leq 0.05}=5$ for sessions 1-12 and $\mathrm{U}_{\mathrm{n} 1=5 ; \mathrm{n} 2=6 ; P \leq 0.05}=3$ for sessions 13 and 14) differences of group means of discrimination performance between lesioned and control animals could be observed from session 2 on (Mann-Whitney $U$ values for sessions 1-14: 18.0, 0.0, 1.0, 4.5, 4.0, 0.0, 0.0, 3.0, 0.5, 2.0, 3.0, 3.0, 0.0, 5.0) (Fig. 4A).

When $\mathrm{CR}+$ rate and $\mathrm{CR}-$ rate were analyzed separately it was revealed that the impairment in discrimination performance in terms of rate of performance development and asymptotic level of performance were mainly due to effects on the $\mathrm{CR}+$ rate rather than the $\mathrm{CR}-$ rate (Fig. $4 \mathrm{~B}, \mathrm{C}$ ): Whereas the control group attained a $>60 \% \mathrm{CR}+$ rate from session 4 on, the lesioned group showed a slower initial development of $\mathrm{CR}+$ rate and a reduced saturation level between $30 \%$ and 50\% (Fig. 4B); group mean values of $\mathrm{CR}+$ rate differed significantly (Mann-Whitney $\mathrm{U}, P<0.05$ ) between lesioned group and controls from session 2 on
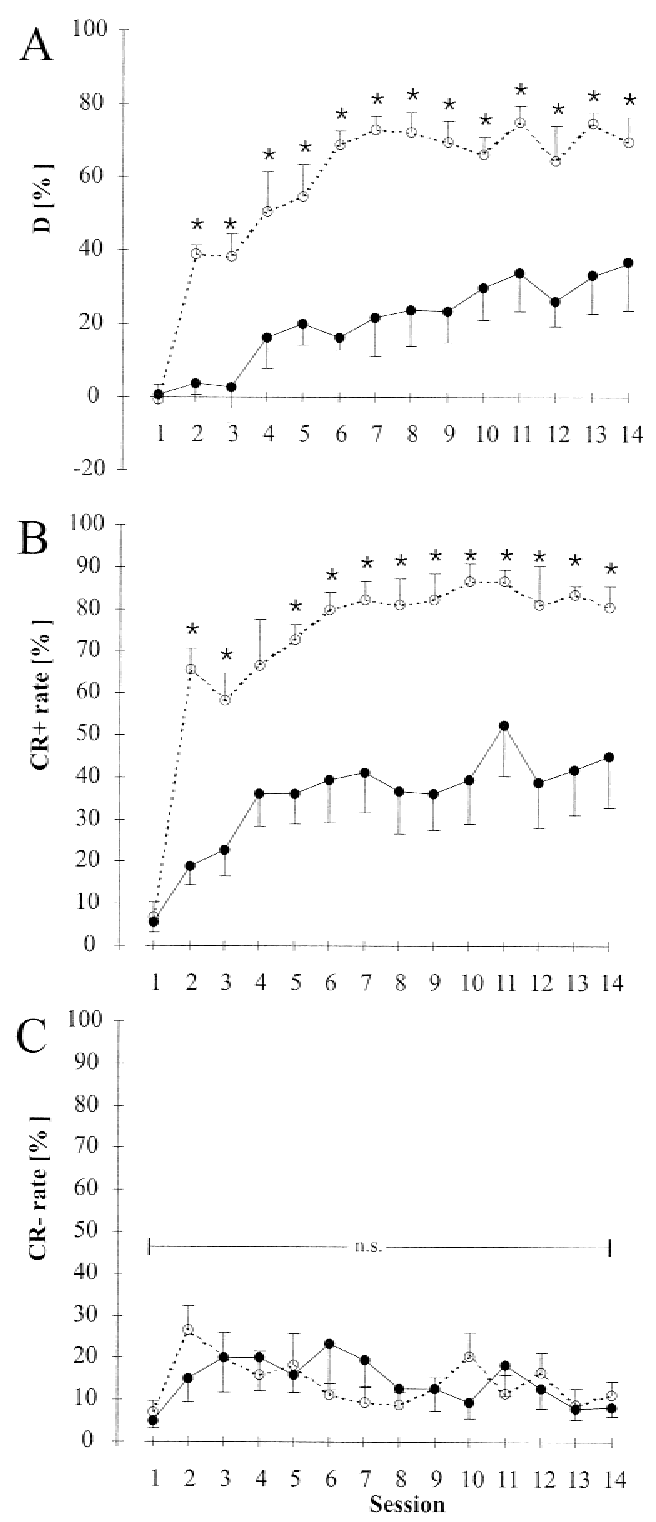

Figure 4: Time courses of FM tone discrimination performance $D(A), C R+$ rate $(B)$, and CR- rate $(C)$ in previously naive lesioned gerbils $(-)$ and sham-lesioned controls $(\bigcirc)$ (experiment B). Plotted are group means $(n=6)$ and standard errors of means. In panel C error bars associated with the data for lesioned group point downward, those associated with the control data point upward. Significant (Mann-Whitney $U, P<0.05$ ) group differences in discrimination performance $D$ and $C R+$ rate are marked with asterisks $\left(^{*}\right)$ and could be found already from session 2 on $(A, B)$. No differences between lesioned and control group were found for the $C R-$ rate $(C)$.

(Mann-Whitney U values for sessions 1-14: 17.5, 0.0, 2.0, 8.0, 0.5, 1.5, 1.0, 3.0, 0.0, 1.0, 4.0, 3.0, 0.0, $3.5)$. The CR- rate stabilized at relative frequencies $<25 \%$ already after session 2 in both lesioned and

$$
\begin{array}{llllllllllllllll}
\hline & E & A & R & N & I & N & G & \boldsymbol{Q} \\
353 & M & E & M & O & R & Y
\end{array}
$$


control animals and showed no significant differences between the groups (Fig. 4C) (Mann-Whitney $U$ values for sessions 1-14: 14.5, 9.0, 17.5, $18.0,17.0,17.5,11.0,14.0,16.0,9.0,15.5,14.0$, 13.5, 14.0). Mean crossing times declined from $5.0 \pm 1.4 \mathrm{sec}$ in session 1 to $3.0 \pm 1.1 \mathrm{sec}$ in session 14 in the lesioned group and from $5.4 \pm 2.1 \mathrm{sec}$ to $2.7 \pm 1.1 \mathrm{sec}$ in the control group with similar temporal development in both groups yielding no significant differences between groups. Intertrial crossing activity did not differ between groups.

\section{EFFECTS OF LESION ON THE RETENTION OF FM TONE DISCRIMINATION (EXPERIMENT C)}

In experiment $\mathrm{C}$ gerbils $(n=11)$ were trained prior to the operation to attain asymptotic discrimination performance with the same stimuli as in experiment B. Discrimination performances were significant (Wilcoxon, $P<0.05$ ) for all animals at least after session 4 but usually after day 2 . Bilateral lesion of auditory cortex was performed by thermocoagulation in seven animals, four animals received sham lesions and served as controls. The operations were carried out after individual discrimination performance was stable for at least three but no more than six consecutive sessions. This amounted to session 7 in two lesioned and two control animals and to session 9 in five lesioned and two control animals. To enable consistent treatment of all cases the first session after the operation will be termed session 1 and used as a reference in the following report.

Preoperative performance development in both the lesioned and control group was similar to earlier results on FM tone discrimination (Wetzel et al. 1998) and corresponded to the values observed in the sham-lesioned group in experiment B. No significant differences existed between these groups; Kruskal-Wallis $\mathrm{H}$ test statistics for the seven sessions preceding operation $(3.1,0.8,1.6$, $0.9,1.8,0.3,3.0$, respectively) all remained well below $\chi_{\mathrm{df}=2 ; P \leq 0.05}^{2}=5.99$. Performance increased over time and reached a plateau at $\sim 70 \%$ discrimination performance (Fig. 5A). The development of performance over time in both lesioned and untreated animals is typically a result of a more or less monotonically increasing $\mathrm{CR}+$ rate (Fig. 5B) and a biphasic rise-fall time course of the $\mathrm{CR}-$ rate reflecting an initial tendency for stimulus generalization followed by a later phase of improved discrimination (Fig. 5C). The larger variances of the $D$ measure and $\mathrm{CR}+$ rate in sessions -9 and -8 is reflective of the smaller number of cases in these two sessions compared to subsequent sessions (see above).

Bilateral lesion of auditory cortex significantly reduced performance in FM tone discrimination whereas sham-lesion controls showed no effect. Differences in group means of performance level $D$ remained significant (Mann-Whitney $\mathrm{U}, P<0.05$, $\mathrm{U}_{\text {crit;n1 }=4 ; \mathrm{n} 2=7 ; P<0.05}=3$ ) for 5 sessions after lesion (Fig. 5A); (U statistics for the 13 sessions following operation: $3,3,2,3,3,10,10,5,5,3,7,3$, 9). A separate analysis of $\mathrm{CR}+$ rate and $\mathrm{CR}-$ rate revealed that discrimination performance declined not because of a reduced $\mathrm{CR}+$ rate but because of an increased $\mathrm{CR}-$ rate induced by lesion (Fig. $5 \mathrm{~B}, \mathrm{C})$. This is reciprocal to the lesion effect on discrimination performance observed in experiment $\mathrm{B}$. Group variances of $\mathrm{CR}+$ rate were less effected by lesion than those of the CR- rate. Sham lesion had no effects on group means or variances of either $\mathrm{CR}+$ rate or $\mathrm{CR}-$ rate. There were no significant effects on crossing times: Over preoperative sessions -9 to -1 crossing times were gradually reduced from $5.3 \pm 2.0 \mathrm{sec}$ to $2.6 \pm 1.3$ sec in the lesioned group and from $3.7 \pm 1.3 \mathrm{sec}$ to $2.5 \pm 1.2 \mathrm{sec}$ in the sham-lesioned group. In postoperative session 1 crossing times were $3.7 \pm 1.6$ sec and $2.8 \pm 1.2 \mathrm{sec}$ for the lesioned and the shamlesioned group, respectively. Lesion had no effect on the inter-trial activity.

As in experiments $\mathrm{A}$ and $\mathrm{B}$, group means of discrimination performance, $\mathrm{CR}+$ rate and $\mathrm{CR}-$ rate well reflected the data obtained for the individual animals except for one case (Fig. 6). This gerbil developed normal discrimination performance ( $D$ measure $\sim 70 \%$ in the last four sessions preceding operation). Performance declined to $17 \%$ in the first session after operation and remained close to zero for rest of the observation time ( 15 sessions), that is, did not show the typical recovery. The initial decline was due to a decrease of $\mathrm{CR}+$ rate rather than increase of $\mathrm{CR}-$ rate. This behavior remained through the second session. From session 3 on both $\mathrm{CR}+$ and $\mathrm{CR}-$ rate increased to levels $>60 \%$ for the next seven consecutive sessions and then were reduced to rates $<60 \%$. This exceptional behavior seemed to reflect a stable generalization across both conditioned stimuli unlike the reacquisition of discrimination performance seen in the other animals. Because the FDG analysis of the lesion showed proper localization and extent corresponding to all other animals this gerbil was not excluded from the

$$
\begin{array}{lllllllllllllll} 
& E & A & R & N & I & N & G & \begin{array}{l}
\boldsymbol{Q} \\
354
\end{array} & M & E & M & O & R & Y
\end{array}
$$




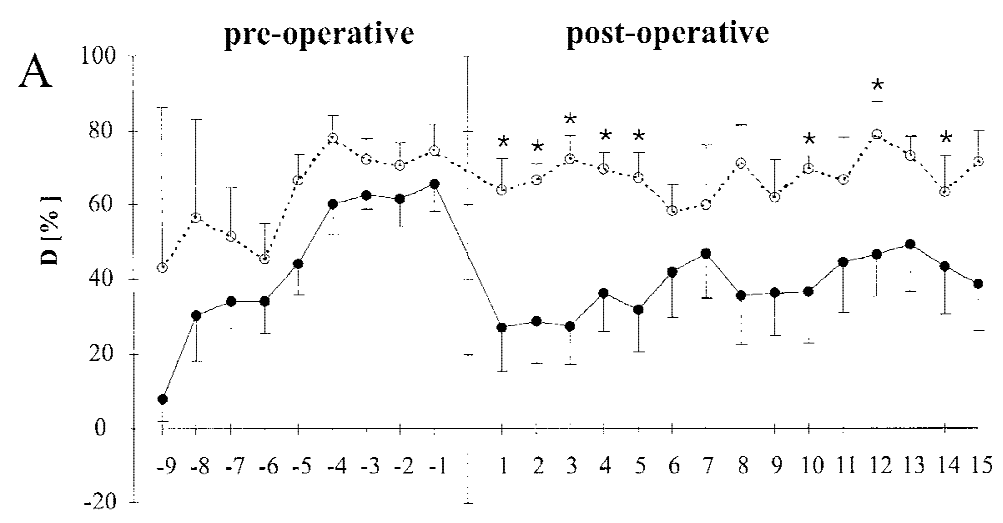

B
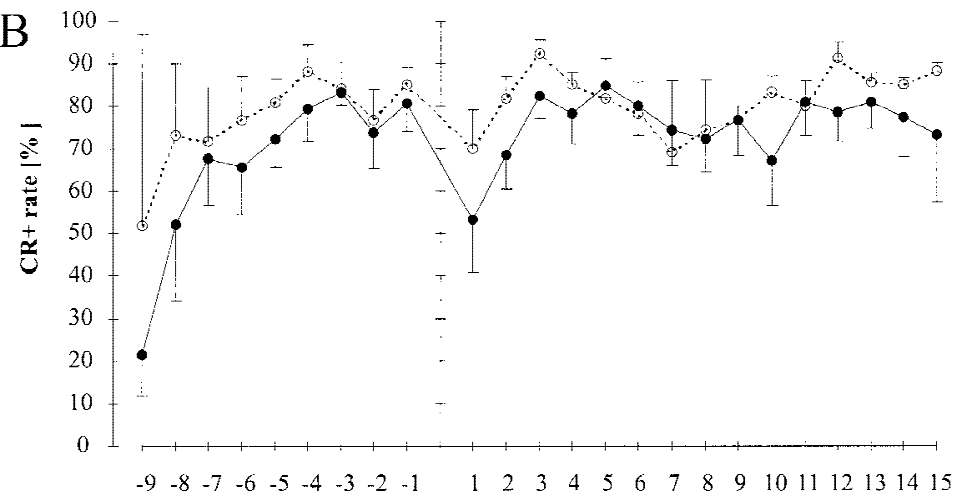

C

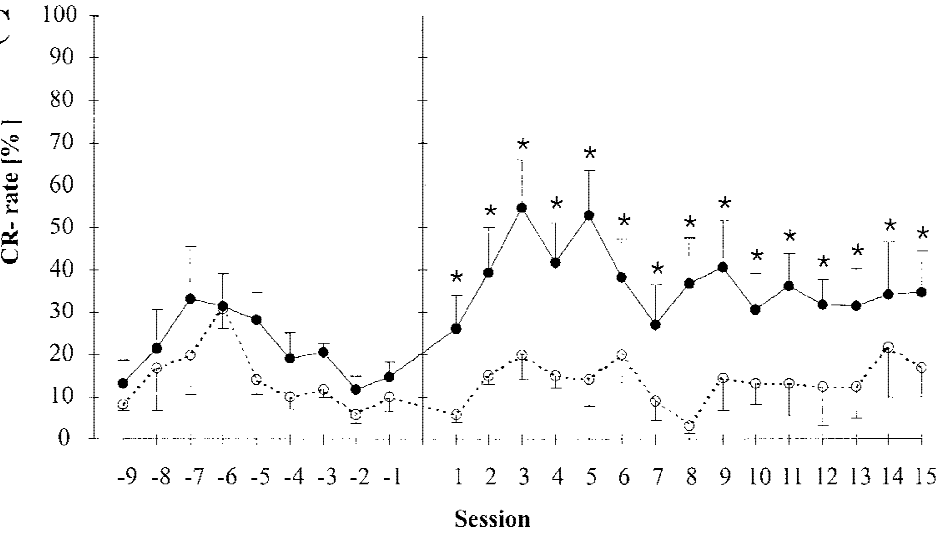

Figure 5: Comparison of lesion effects on discrimination performance $D(A), \mathrm{CR}+$ rate $(B)$, and $C R-$ rate $(C)$ in a previously trained group (experiment C). ( ) Lesioned gerbils; (○) sham-lesioned controls. Plotted are the group means plus standard errors of means against training session number relative to the time point of lesion operation (vertical bar). (A) After the cortical ablation discrimination performance was reduced from $>60 \%$ to $<30 \%$. Performance was reduced for all subsequent sessions and reached significance (Mann-Whitney $U, P<0.05$, indicated by asterisks, *) for 5 consecutive sessions after the operation. $\mathrm{CR}+$ rate was not significantly affected by cortical ablation $(B)$. The CS- rate showed a significant $(*)$ increase in the lesioned group compared to controls for the entire observation time of 15 sessions $(C)$. analysis. The low discrimination performance from session 2 on was caused by a striking covariance between $\mathrm{CR}+$ rate and $\mathrm{CR}-$ rate. Because an outlier test performed on the change of discrimination performance from pre-operative to post-operative performance confirmed the aberrant behavior in this animal (Dixon outlier test, $M=0.581>\mathrm{M}_{\text {crit } ; n=7}=0.507$ ) we also calculated the Mann-Whitney statistic for a difference in discrimination performance between the lesioned and control group with the aberrant animal removed. Because of the extreme location of the values contributed by the outlier animal the rank statistics of the corrected sample re- mained unchanged. For the one-sided test with $\mathrm{U}_{\text {crit;n1 }}=6 ; \mathrm{n} 2=4 ; P \leq 0.05=3$ specified significances in Figure 5 remain the same.

\section{Discussion}

The results of the present study show that bilateral ablation of auditory cortex in Mongolian gerbil has no effect on the acquisition of differentially conditioned GO/NO-GO responses to pure tones. However, lesion impairs the acquisition of differentially conditioned responses to FM tones by reducing rate of development and asymptotic level of the $\mathrm{CR}+$. In pretrained animals bilateral auditory

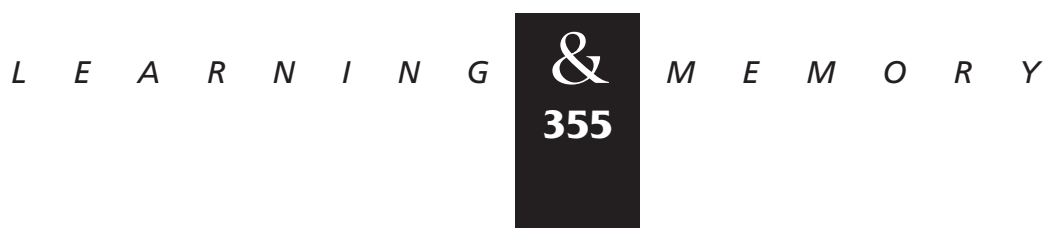




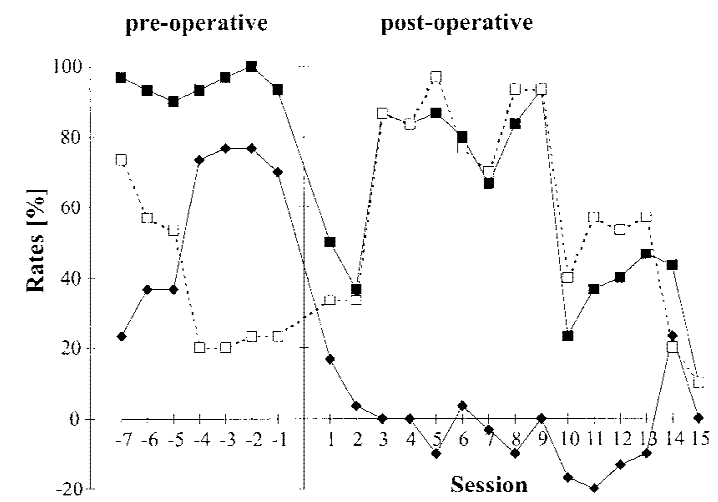

Figure 6: Aberrant time courses of discrimination performance $D(\diamond), C R+$ rate $(\mathbf{\square})$, and CR- $(\square)$ rate of one gerbil that received bilateral lesion of auditory cortex after FM tone discrimination training. Before the bilateral auditory cortex ablation this animal showed normal development of FM tone discrimination (session with negative indices). From session 2 on after the ablation this gerbil showed a high covariance between $\mathrm{CR}+$ rate and CR- rate yielding a discrimination performance $D$ close to zero, which was atypical for the other animals.

cortex ablation impairs the retention or retrieval of FM tone discrimination by increasing the CR-. The results are interpreted to indicate more relevant involvement of auditory cortex in discrimination and/or differential conditioning to FM tones than in discrimination and/or conditioning to pure tones. In the following discussion we first attend to interpretative problems of the lesion method as related to the present study and then focus on the role of auditory cortex in the studied experimental paradigm.

\section{LESION METHOD}

In addition to the recording and electrical stimulation of neuronal activity, lesion studies constitute an important method to demonstrate physiological involvement of localized brain areas for sensory processing, behavioral functions, learning, and memory (Thompson 1983; Olton 1986; Isaacson 1988) despite the principal incapacity of the lesion method to identify the lesioned brain areas as essential for these functions (e.g., Grobstein 1990). The latter fact might in part explain the divergent views reported in the literature about the relevance of auditory cortex in learning and sensory discrimination as deduced from results of lesion experiments. A more general agreement about the role of auditory cortex on the basis of lesion experiments, however, is hampered by differences in experimental species, conditioned stimuli and the particular discrimination task, and details of the behavioral procedure as well as extent and localization of lesion across studies. For all of these parameters critical involvement in determining effectiveness of lesion have been demonstrated (see below). A further complication in the attempt to delineate the role and relevance of auditory cortex in FM tone processing with lesions lies in the fact that it is not clear if interference with learning and memory mechanisms or rather a sensory, emotional, or motor aspect of the task or even a particular interaction between any of these aspects is mainly responsible for observed performance deficits. The remaining part of this subsection addresses these objections individually.

To what extent effects of auditory cortex lesions reflect deficits in sensory processing, particularly in hearing thresholds, is still debated. Early work pointed to an ineffectiveness of auditory cortex lesions in destroying performance in auditory tasks involving detection of sound onset (Kryter and Ades 1943; Meyer and Woolsey 1952), change in sound intensity (Raab and Ades 1946; Rosenzweig 1946; Oesterreich et al. 1971) or change in tone frequency (Butler et al. 1957; Goldberg and Neff 1961). It was concluded that auditory cortical ablations had no effect on the absolute thresholds (e.g., Neff et al. 1975). More recently, the role of auditory cortex for hearing thresholds has been reconsidered on the basis of refined experiments with Japanese Macaques revealing clear effects on hearing thresholds (Heffner and Heffner 1986, 1989a,b, 1990a) as have been reported for auditory cortex damage in humans (e.g., Michel et al. 1980; for review, see Graham et al. 1980). Despite the fact that the question of lesion effects on hearing thresholds is not finally settled it is unlikely that potential threshold effects played any major role in the impairment of FM tone discrimination reported in the present study as pure tone discrimination was not at all affected. It is nevertheless conceivable that a purely sensory aspect of FM tone discrimination not occurring in pure tone discrimination caused for the observed effects (see below). Such a discrimination deficit should, however, pertain to stimulus selectivity rather than stimulus sensitivity as indicated by hurdle crossing elicited by both the CS+ and the CS- in experiment C.

In the present study, it is unlikely that emotional, motivational, or motor disturbances potentially induced by the lesion played a role in the

$$
\begin{array}{lllllllllllllll}
L & E & A & R & N & I & N & G & \underset{356}{\mathbf{Z}} & M & E & M & O & R & Y
\end{array}
$$


observed effects. Motor disturbances or a motivation deficit to avoid the US can be ruled out because of the unaffected hurdle crossing behavior in response to the CS+ after the lesion and the ineffectiveness of the lesion to interfere with the discrimination of pure tones in experiment $A$. It is also unlikely that arousal might have played a significant role in the observed failure to inhibit the $\mathrm{CR}-$ after the lesion in experiment $\mathrm{C}$ as no parallel effect on the $\mathrm{CR}+$ rate could be observed nor was the intertrial crossing rate increased after the lesion.

Generally, effects of auditory cortex lesion depend on the particular task used for testing performance. This has been noted in sound source localization paradigms (Heffner 1978; Heffner and Masterton 1978; Kelly and Glazier 1978; Kelly 1980; Kelly and Kavanagh 1986; Beitel and Kaas 1993; Beitel 1997) where it seems that the effect of cortical lesions depends specifically on the paradigm's demand on the animal's ability to integrate spatial sensory information with certain motor responses (e.g., Phillips and Gates 1982) and the specific perceptual realization that sounds are associated with locations in space (Heffner and Heffner 1990b). In the present study, even under the assumption that purely sensory lesion effects played no role for the performance deficits, it is conceivable that specifically the integration of FM tone perception with the particular motor response but not the integration of pure tone perception with the motor response was impaired. The problem that the involvement of deficits in discrete functional concepts such as sensory processing, sensomotor integration, or learning and memory frequently are not delineated satisfactorily by lesion studies is generally noted (e.g., Colombo et al. 1990) but usually attributed to the limited experimental possibilities of separation of potentially effective variables. It should not be overlooked, however, that such functional entities are to a degree arbitrarily defined and need not in all cases be reflected in neurophysiological mechanisms in the form of simple one-to-one relations.

DIFFERENTIAL EFFECTS OF LESION ON AQUISITION OF PURE TONE DISCRIMINATION AND FM TONE DISCRIMINATION

The observation that bilateral auditory cortex ablation in the Mongolian gerbil does not impair performance of pure tone discrimination is in correspondence with reports on other species (e.g., rat: LeDoux 1990; cat: Meyer and Woolsey 1952; Thompson 1960; Goldberg and Neff 1961; Dewson 1964; Kelly 1973; monkey: Evarts 1952; Massopust et al. 1965). In contrast, it was reported for rabbits that auditory cortex ablation affects acquisition (Teich et al. 1988), retention (Jarrell et al. 1987), and extinction (Teich et al. 1989) of heart rate conditioning to pure tones. Such differing results could reflect species differences as well as differences in the CRs and the experimental methods to assess them. Specifically, it is not self evident that the acquisition of a conditioned autonomic response, such as a change in heart rate, and the acquisition of a complex motor response, as in the present experiment, make similar demands on the auditory cortex in a given species. Moreover, for a given species, even if the motor response required by a task is the same, the effectiveness of cortical lesion in impairing performance in pure tone discrimination still depends on details of the behavioral procedure. It is known, for example, that relearning of frequency discrimination after bilateral auditory cortex ablation in cats was possible if training required response to a change of stimulus from a constant background stimulation but did not occur if training was based on a GO/NO-GO logic or used false alarm punishment (Thompson 1960; Neff 1961). It was generally observed that both acquisition and performance level suffer from auditory cortical lesions more in discrimination tasks than in detection tasks (Elliott and Trahiotis 1972).

In the present study it cannot be finally excluded that lesion-induced failure in FM tone discrimination is based on a failure to discriminate very brief pure tones that might be selected by the animal from any segment the FM tone, for example, the beginning or the end of the FM tone. However, despite the multivariate dependence of the effectiveness of bilateral auditory cortex ablation, the general view has emerged that cortex ablation seems to affect discrimination of more complex stimuli to a higher degree than discrimination of simpler stimuli. For example, Dewson (1964) found that bilateral ablation of the insulotemporal cortex in the cat destroyed the ability to discriminate vowels but not the frequency discrimination. Kelly (1973) demonstrated (1) ineffectiveness of bilateral insulotemporal cortex lesions to block tone onset detection and pure tone frequency discrimination, (2) a detectable but moderate impairment of FM tone discrimination, and (3) nearly complete abolishment of two-tone sequence dis-

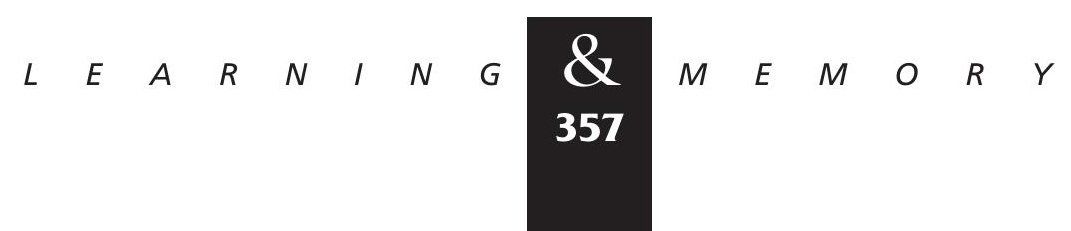


crimination. Cranford et al. (1976) reported unaffected hearing thresholds but impairment in click rate discrimination after bilateral auditory cortex ablation in cats. Waikita (1996) found that neonatally lesioned rats show no deficits in tone presentation detection but clear deficits in pulse rate discrimination. Our finding that differential conditioning to FM tones is impaired by auditory cortical ablations, whereas differential conditioning to pure tones is not, is in basic correspondence with this view. Specifically, it suggests that in the gerbil, auditory cortex is involved in a particular sensory, sensomotor integrative, or learning- and memoryrelated aspect of FM tone processing that is not recruited with the same relevance in pure tone processing.

The question of which characteristic of FM tones, not present in pure tones, might be responsible for this difference arises. It has been noted that even relatively small cortical lesions are particularly destructive if the task involved the discrimination of auditory stimuli that differed only in the temporal order of stimulus components (Elliott and Trahiotis 1972). This is particularly evident in the effectiveness of auditory cortex lesions to interfere with discriminations between sequences of pure tones (Diamond and Neff 1957; Kelly 1973). To explain this fact Neff (1961) suggested that stimuli that differ only in the temporal order of their components might activate largely the same subsets of neurons in the auditory cortex only in different temporal order. Under this precondition, a small lesion, when properly placed, might interfere with the discrimination of such stimuli more than with the discrimination of stimuli that activate different neural assemblies (see also Sakurai 1998). This view was supported by the finding that the effects of cortical lesion on the discrimination of stimuli that differ only in their duration resembles the effects for pure tone pattern discrimination (Scharlock et al. 1965). We are presently investigating to what extent time-mirroring of a linearly FM tone changes the spatial and temporal characteristics of an excited neuronal population in gerbil auditory cortex and how these different representations might be changed by FM tone discrimination learning. It is known from the auditory cortex analog of the chick that FM tones that differed in the direction of frequency modulation elicited metabolic labeling patterns that slightly differed in the position along the tonotopic axis (Heil and Scheich 1992).

The failure of bilateral auditory cortex ablation to impair differential pure tone conditioning appears to be in conflict with results demonstrating learning-related changes of neuronal activity in auditory cortex. This results include the demonstration of learning-induced distortions in cortical maps (Gonzalez-Lima and Scheich 1986; Recanzone et al. 1993; Scheich et al. 1993b, 1997), increases of (CS+)-evoked firing probability relative to CS- pure tones (Edeline et al. 1993; Weinberger et al. 1993), complex patterns of increases and decreases of (CS+)-evoked firing probability (Kraus and Disterhoft 1982; Diamond and Weinberger 1989; Ohl and Scheich 1996), enhancement of spectral gradients of single unit's receptive fields in the local neighborhood of the CS+ frequency (Ohl and Scheich 1996), as well as learning-induced temporal modulations of firing probability (Ohl and Scheich 1997a). Although the present results rule out an essential contribution of cortical plasticity to acquisition of pure tone discrimination in the used paradigm, it is conceivable that plastic effects in auditory cortex serve other functions that are not recruited in the present task. There are no data available yet about cortical single unit plasticity during differential conditioning to FM tones. However, the temporal modulations of firing probability observed by Ohl and Scheich (1997a) indicate the existence of plastic excitatory and inhibitory influences on cortical units that interact with each other on a fast (millisecond) time scale. These plastic interactions might play a role in learning FM tone discrimination and contribute to the higher relevance of auditory cortex in this task as compared to pure tone discrimination.

The sometimes observable tendency for relearning the FM discrimination indicates that it is possible for other brain structures than auditory cortex to mediate a modest degree of FM discrimination. Generally and across cases however a slight and slow increase of discrimination performance did not attain the level of the control animals (Fig. 5A).

\section{DIFFERENT EFFECTS OF LESION ON FM TONE DISCRIMINATION BETWEEN THE AQUISITION AND THE RETENTION EXPERIMENT}

Experiments B and C revealed impairment of acquisition and retention measures of FM tone discrimination, respectively, after bilateral auditory cortex ablation. The impairment was however due to different mechanisms in both cases. Whereas in the case of acquisition training the lesion affected

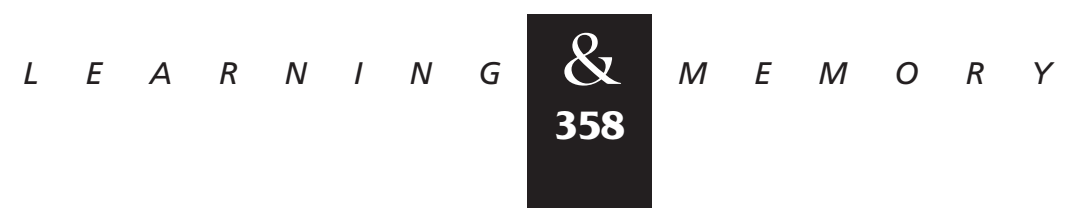


$\mathrm{CR}+$ rate development and asymptotic level, in the retention experiment the effect was due to an increased CR- rate. This result is similar to the study of Kelly and Whitfield (1971) on effects of auditory cortex lesions on FM tone discrimination in the cat. The authors used a "detection discrimination" task, that is, animals had to detect a change from a sequence of FM tone pulses with rising frequency (safe signal) to a sequence of FM tone pulses with falling frequency (warning). It was found that lesion impaired acquisition of FM tone discrimination in previously untrained cats mainly by delaying development and reducing level of reactions toward the warning signal without increasing reactions toward safe signal. Although lesions in trained cats also reduced $\mathrm{CR}+$ rates the authors demonstrated increased CR- rates not seen in the animals that were naive prior to lesion. Similar effects were described in a subsequent study comparing lesion effects on FM tone discrimination with discrimination of sequences of two pure tones (Kelly 1973).

These observations are compatible with the hypothesis of a cortical role in inhibiting the CRduring retention (or retrieval). This interpretation was also favored to explain results in differentially conditioned bradycardia in the rabbit (Jarrell et al. 1987). However, in the acquisition of differential heart rate conditioning (Teich et al. 1988), it was found that ablation-induced loss of conditioning was also due to an increase of $\mathrm{CR}$ - rates rather than a decrease in $\mathrm{CR}+$ rate as in the present experiment. With respect to differentially conditioned bradycardia in the rabbit our results resemble more the effects of lesioning the medial part of the medial geniculate nucleus than of lesioning the auditory cortex. These thalamic lesions attenuated the $\mathrm{CR}+$ in the acquisition experiment (Jarrell et al. 1986) and increased the CR- in the retention experiment (Jarrell et al. 1987). This result was interpreted by the authors as a differential involvement of the medial division of the medial geniculate nucleus in acquisition and retention training. It is conceivable that a similar difference was operative in producing the differential effects in experiment $\mathrm{B}$ and $\mathrm{C}$ in the present study.

Without reference to learning and memory effects, the results are compatible with the hypothesis of a sensory deficit induced by the ablation affecting FM tone selectivity and not FM tone sensitivity. Under this hypothesis, in the lesioned naive animals (experiment $B$ ) the acquisition rate and level were reduced because the animals would en- counter difficulty in discriminating the CS+ and the CS-. They would still realize the onset of a perceived but not discriminated conditioned stimulus. Because the latter would signal the onset of an US in only $50 \%$ of the cases a reduced tendency to acquire hurdle crossing behavior would be expected (Fig. 4B). The trained animals (experiment C), however, have already adopted the strategy of hurdle crossing to avoid foot shock after CS+ presentation. If now the lesion would interfere with the discrimination of $\mathrm{CS}$, a broader generalization across stimuli could be the consequence leading to an increased tendency for hurdle crossing already after CS- presentation (Fig. 5C).

In summary, it appears evident that the auditory cortex in the Mongolian gerbil plays a more important role in discrimination and/or discrimination learning of FM tones than of pure tones. This role could either be of a more sensory nature or more related to learning and memory mechanisms. The former case implies that lesion impairs the sensitivity less than the selectivity to FM tones. In the latter case differential lesion effects on acquisition and retention have to be postulated. Because the understanding of the role of a brain structure seems to depend on the proper apprehension of the roles of other interacting structures, as has been exemplified for example in eye-lid conditioning (e.g., Thompson 1997) or classical fear conditioning (LeDoux 1990, 1993), a more precise characterization of the nature of the auditory cortical role in FM tone discrimination learning and performance must await further analysis of the remaining circuits involved.

\section{Acknowledgments}

We thank Kathrin Buckisch, Ute Lerke, Lydia Löw, Elke Müller and Janet Thunert for their skillful technical assistance in all aspects of the experiment and manuscript preparation, as well as Drs. P. Heil and H. Schulze for critical reading of the manuscript. This research was supported by the Deutsche Forschungsgemeinschaft (We2104/2-1).

The publication costs of this article were defrayed in part by payment of page charges. This article must therefore be hereby marked "advertisement" in accordance with 18 USC section 1734 solely to indicate this fact.

\section{References}

Aitkin, L. 1990. The auditory cortex. Chapman and Hall, London, UK.

Bailey, P.J. 1979. Aspects of categorical processing of speech sounds in man: On the determinants of phonetic category boundaries. In Hearing mechanisms and speech (ed. O. Creutzfeldt), pp. 301-317. Springer-Verlag, New York, NY. 


\section{Ohl et al.}

Beitel, R.E. 1997. Contribution of auditory cortex to acoustical orientation in cats under conditions of discordant auditory reafference. J. Neurophysiol. 78: 3468-3474.

Beitel, R.E. and J.H. Kaas. 1993. Effects of bilateral and unilateral ablation of auditory cortex in cats on the unconditioned head orienting response to acoustic stimuli. J. Neurophysiol. 70: 351-369.

Brown, K.A., J.S. Buchwald, J.R. Johnson, and D.J. Mikolich. 1978. Vocalization in the cat and kitten. Dev. Psychobiol. 11: $559-570$.

Bullock, T.H. 1997. Comparative physiology of acoustic and allied central analyzers. Acta Otolaryngol. Suppl. (Stockh.) 532: $13-21$.

Butler, R.A., I.T. Diamond, and W.D. Neff. 1957. Role of auditory cortex in discrimination of changes in frequency. J. Neurophysiol. 20: 108-120.

Cahill, L., F. Ohl, and H. Scheich. 1996. Alteration of auditory cortex activity with a visual stimulus through conditioning: A 2-deoxyglucose analysis. Neurobiol. Learn. Mem. 65: 213-222.

Clarey, J.C., P. Barone, and T.J. Imig. 1992. Physiology of thalamus and cortex. In The mammalian auditory pathway: Neurophysiology (ed. A.N. Popper and R.R. Fay), pp. 232-334, Springer-Verlag, New York, NY.

Collias, N. and M. Joos. 1953. The spectrographic analysis of sound signals of the domestic fowl. Behavior 5: 175-188.

Colombo, M., M.R. D'Amato, H.R. Rodman, and C.G. Gross. 1990. Auditory association cortex lesions impair auditory short-term memory in monkeys. Science 247: 336-338.

Cranford, J.L., M. Igarashi, and J.H. Strambler. 1976. Effect of auditory neocortex ablation on identification of click rates in cats. Brain Res. 116: 69-81.

Dewson, J.H. 1964. Speech sound discrimination by cats. Science 144: 555-556.

Diamond, D.M. and N.M. Weinberger. 1989. Role of context in the expression of learning-induced plasticity of single neurons in auditory cortex. Behav. Neurosci. 103: 471-494.

Diamond, I.T. and W.D. Neff. 1957. Ablation of temporal cortex and discrimination of auditory patterns. J.

Neurophysiol. 20: 300-315.

Edeline, J.M., P. Pham, and N.M. Weinberger. 1993. Rapid development of learning-induced receptive field plasticity in the auditory cortex. Behav. Neurosci. 107: 539-551.

Ehret, G. 1997. The auditory cortex. J. Comp. Physiol. A 181: $547-557$.

Elliott, D.N. and C. Trahiotis. 1972. Cortical lesions and auditory discrimination. Psychol. Bull. 77: 198-222.
Esser, K.H. and B. Lud. 1997. Discrimination of sinusoidally frequency-modulated sound signals mimicking species-specific communication calls in the FM-bat Phyllostomus discolor. J. Comp. Physiol. A 180: 513-522.

Evarts, E.V. 1952. Effect of auditory cortex ablation on frequency discrimination in monkey. J. Neurophysiol. 15: 443-448.

Fitch, R.H., S. Miller, and P. Tallal. 1997. Neurobiology of speech perception. Annu. Rev. Neurosci. 20: 331-353.

Goldberg, J.M. and W.D. Neff. 1961. Frequency discrimination after bilateral ablation of cortical auditory areas. J. Neurophysiol. 24: 119-128.

Gonzalez-Lima, F. and H. Scheich.1986. Neural substrates for tone-conditioned bradycardia demonstrated with 2-deoxyglucose. II. Auditory cortex plasticity. Behav. Brain Res. 20: 281-293.

Graham, J., R. Greenwood, and B. Lecky. 1980. Cortical deafness: A case report and review of the literature. J. Neurol. Sci. 48: 35-49.

Grobstein, P. 1990. Strategies for analyzing complex organization in the nervous system: I. Lesions experiments. In Computational neuroscience (ed. E.L. Schwartz), pp. 19-37. MIT Press, Cambridge, MA.

Heffner, H. 1978. Effect of auditory cortex ablation on localization and discrimination of brief sounds. J. Neurophysiol. 41: 963-976.

Heffner, H.E. and R.S. Heffner. 1986. Hearing loss in Japanese Macaques following bilateral auditory cortex lesions. J. Neurophysiol. 55: 256-271.

1989a. Cortical deafness cannot account for the inability of Japanese Macaques to discriminate species-specific vocalizations. Brain and Language 36: $275-285$.

1989b. Effect of restricted cortical lesions on absolute thresholds and aphasia-like deficits in Japanese Macaques. Behav. Neurosci. 103: 158-169.

1990a. Effect of bilateral auditory cortex lesions on absolute thresholds in Japanese Macaques. J. Neurophysiol. 64: 191-205.

1990b. Effect of bilateral auditory cortex lesions on sound localization in Japanese Macaques. J. Neurophysiol. 64: 915-931.

Heffner, H. and B. Masterton. 1978. Contribution of auditory cortex to sound localization in the Monkey (Macaca mulatta). J. Neurophysiol. 38: 1340-1358.

Heffner, R.S. 1997. Comparative study of sound localization and its anatomical correlates in mammals. Acta Otolaryngol. Suppl. (Stockh.) 532: 46-53. 
Heil, P. and H. Scheich. 1992. Spatial representation of frequency-modulated signals in the tonotopically organized auditory cortex analogue of the chick. J. Comp. Neurol. 322: 548-565.

Hess, A. and H. Scheich. 1996. Optical and FDG mapping of frequency-specific activity in auditory cortex. Neuroreport 7: 2643-2647.

Holman, W.T. and W.T. Seale. 1991. Ontogeny of sexually dimorphic ultrasonic vocalization in Mongolian gerbils. Dev. Psychobiol. 24: 103-115.

Isaacson, R.L. 1988. Brain lesion studies related to memory: A critique of strategies and interpretations. In Information processing in the brain (ed. H.J. Markowitsch), pp. 87-105. Hans Huber Publications, Toronto, Ontario, Canada.

Jarrell, T.W., C.G. Gentile, P.M. McCabe, and N. Schneiderman. 1986. The role of the medial geniculate region in differential Pavlovian conditioning of bradycardia in rabbits. Brain Res. 374: 126-136.

Jarrell, T.W., C.G. Gentile, L.M. Romanski, P.M. McCabe, and N. Schneiderman. 1987. Involvement of cortical and thalamic auditory regions in retention of differential bradycardiac conditioning to acoustic conditioned stimuli in rabbits. Brain Res. 412: 285-294.

Kelly, J.B. 1973. The effects of insular and temporal lesions in cats on two types of auditory pattern discrimination. Brain Res. 62: 71-87.

1980. Effects of auditory cortical lesions on sound localization by the rat. J. Neurophysiol. 44: 1161-1174.

Kelly, J.B. and S.J. Glazier. 1978. Auditory cortex lesions and discrimination location by the rat. Brain Res. 145: 315-321.

Kelly, J.B. and G.L. Kavanagh. 1986. Effects of auditory cortical lesions on pure-tone sound localization by the Albino rat. Behav. Neurosci. 100: 569-575.

Kelly, J.B. and I.C. Whitfield. 1971. Effects of auditory cortical lesions on discrimination of rising and falling frequency-modulated tones. J. Neurophysiol. 34: 802-816.

Kraus, N. and J.F. Disterhoft. 1982. Response plasticity of single neurons in rabbit auditory association cortex during tone-signaled learning. Brain. Res. 246: 205-215.

Kryter, K.D. and H.W. Ades. 1943. Studies on the function of the higher acoustic nervous centers in the cat. Amer. Am. J. Psychol. 56: 501-536.

LeDoux, J.E. 1990. Information flow from sensation to emotion: Plasticity in the neural computation of stimulus value. In Learning and computational neuroscience: Foundations of adaptive networks (ed. M. Gabriel and J. Moore), pp. 3-51. MIT Press, Cambridge, MA.

1993. Emotional memory systems in the brain. Behav. Brain Res. 58: 69-79.
Liberman, A.M. and M. Studdert-Kennedy. 1978. Phonetic perception. In Handbook of sensory physiology (ed. R. Held, H.W. Leibowitz, and H.L. Teuber), pp. 143-178. Springer-Verlag, New York, NY.

Massopust, L.C., Jr., H.W. Barnes, and J. Bidura. 1965. Auditory frequency discrimination in cortically ablated monkeys. J. Aud. Res. 5: 85-93.

Meyer, D.R. and C.N. Woolsey. 1952. The effect of localized cortical destruction upon auditory discriminative conditioning in the cat. J. Neurophysiol. 15: 149-162.

Michel, F., F. Peronnet, and B. Schott. 1980. A case of cortical deafness: clinical and electrophysiological data. Brain Lang. 10: 367-377.

Neff, W.D. 1961. Neural mechanisms of auditory discrimination. In Sensory communication (ed. W. Rosenblith), pp. 259-278. Wiley, New York, NY.

Neff, W.D., I.T. Diamond, and J.H. Cassedy. 1975. Behavioral studies of auditory discrimination: central nervous system. In Handbook of sensory physiology. Auditory system, Vol. V (ed. W.D. Keidel and W.D. Neff), pp. 307-400. Springer-Verlag, New York, NY.

Newman, J.D. 1978. Perception of sounds used in species-specific communication: The auditory cortex and beyond. J. Med. Primatol. 7: 98-105.

Oesterreich, R.E., N.L. Strominger, and W.D. Neff. 1971. Neural structures mediating differential sound intensity discrimination in the cat. Brain Res. 27: 251-270.

Ohl, F. and H. Scheich. 1996. Differential frequency conditioning enhances spectral contrast sensitivity of units in auditory cortex (field Al) of the alert Mongolian Gerbil. Eur. J. Neurosci. 8: 1001-1017.

Ohl, F.W. and H. Scheich. 1997a. Learning-induced dynamic receptive field changes in auditory cortex $(\mathrm{Al})$ of the unanaesthetized Mongolian Gerbil. J. Comp. Physiol. A 181: 685-696.

1997b. Orderly cortical representation of vowels based on formant interaction. Proc. Natl. Acad. Sci. 94: 9440-9444.

Olton, D.S. 1986. Interventional approaches to memory: Lesions. In Learning and memory. A biological view (ed. J.R. Martinez and R.P. Kesner), pp. 379-397. Academic Press, Orlando, FL.

Phillips, D.P. and G.R. Gates. 1982. Representation of the two ears in the auditory cortex: A re-examination. Int. J. Neurosci. 16: 41-46.

Phillips, D.P., R.A. Reale, and J.F. Brugge. 1991. Stimulus processing in the auditory cortex. In Neurobiology of hearing. The central auditory system (ed. R.A. Altschuler, R.P. Bobbin, B.M. Clopton, and D.W. Hoffman), pp. 335-365. Raven Press, New York, NY.

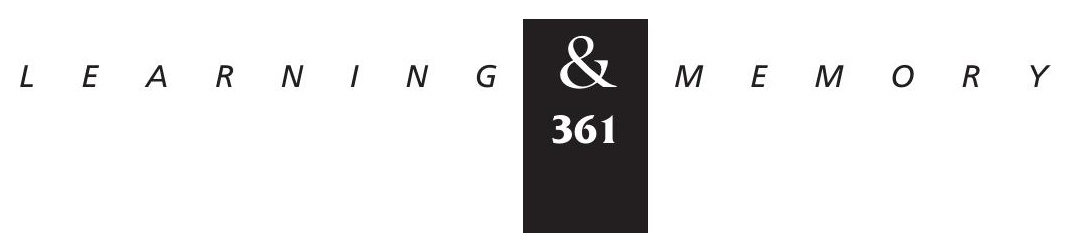




\section{Ohl et al.}

Raab, D.H. and H.W. Ades. 1946. Cortical and midbrain mediation of a conditioned discrimination of acoustic intensities. Am. J. Psychol. 59: 59-83.

Recanzone, G.H., C.E. Schreiner, and M.M. Merzenich. 1993. Plasticity in the frequency representation of primary auditory cortex following discrimination training in adult owl monkeys. J. Neurosci. 13: 87-103.

Rosenzweig, M. 1946. Discrimination of auditory intensities in the cat. Am. J. Psychol. 59: 127-136.

Ryan, A.F., N.K. Woolf, and F.R. Sharp. 1982. Tonotopic organization in the central auditory pathway of the Mongolian gerbil: a 2-deoxyglucose study. J. Comp. Neurol. 207: 369-380.

Ryan, A.F., S. Braverman, N.K. Woolf, and G.A. Axelsson. 1989. Auditory neural activity evoked by pure tone stimulation as a function of intensity. Brain Res. 483: 283-293.

Sakurai, Y. 1998. The search for cell assemblies in the working brain. Behav. Brain Res. 91: 1-13.

Scharlock, D.P., W.D. Neff, and N.L. Strominger. 1965. Discrimination of tone duration after bilateral ablation of cortical auditory areas. J. Neurophysiol. 28: 673-681.

Scheich, H. 1991. Auditory cortex: Comparative aspects of maps and plasticity. Curr. Opin. Neurobiol. 1: 236-247.

Scheich, H., P. Heil, and G. Langner. 1993a. Functional organization of auditory cortex in the Mongolian gerbil (Meriones unguiculatus). II. Tonotopic 2-deoxyglucose. Eur. J. Neurosci. 5: 898-914.

Scheich, H., C. Simonis, F. Ohl, J. Tillein, and H. Thomas. 1993b. Functional organization and learning-related plasticity in auditory cortex of the Mongolian gerbil. Prog. Brain Res. 97: 135-143.

Scheich, H., H. Stark, W. Zuschratter, F.W. Ohl, and C.E. Simonis. 1997. Some functions of primary auditory cortex in learning and memory formation. Adv. Neurol. 73: 179-193.

Schulze, H., F. Ohl, P. Heil, and H. Scheich. 1997. Field specific responses in the auditory cortex of the unanaesthetized Mongolian Gerbil to tones and slow frequency modulations. J. Comp. Physiol. A 181: 573-589.

Setzer, U. 1992. "Die Abbildungseigenschaften artspezifischer Ultraschall-Vokalisationen im auditorschen Cortex der Mongolischen Wüstenrennmaus (Meriones unguiculatus)." M.Sc. thesis, TU Darmstadt, Darmstadt, Germany.

Stefanatos, G.A., G.G.R. Green, and G.G. Ratcliff. 1989. Neurophysiological evidence of auditory channel anomalies in developmental dysphasia. Arch. Neurol. 46: 871-875.

Suga, N. 1968. Analysis of frequency-modulated and complex sounds by single auditory neurones of bats. J. Physiol. (Lond.) 198: 51-80.
Sugimoto, S., M. Sakurada, J. Horikawa, and I. Taniguchi. 1997. The columnar and layer-specific response properties of neurons in the primary auditory cortex of Mongolian gerbils. Hear. Res. 112: 175-185.

Teich, A.H., P.M. McCabe, C.G. Gentile, T.W. Jarrell, R.W. Winters, D.R. Liskowsky, and N. Schneiderman. 1988. Role of auditory cortex in the acquisition of differential heart rate conditioning. Physiol. Behav. 44: 405-412.

Teich, A.H., P.M. McCabe, C.C. Gentile, L.S. Schneiderman, R.W. Winters, D.R. Liskowsky, and N. Schneiderman. 1989. Auditory cortex lesions prevent the extinction of Pavlovian differential heart rate conditioning to tonal stimuli in rabbits. Brain Res. 480: 210-218.

Thomas, H., J. Tillein, P. Heil, and H. Scheich. 1993. Functional organization of auditory cortex in the Mongolian gerbil (Meriones unguiculatus). I. Electrophysiological mapping of frequency representation and distinction of fields. Eur. J. Neurosci. 5: 882-897.

Thompson, R. 1983. Brains systems and long-term memory. Behav. Neurol. Biol. 37: 1-45.

Thompson, R.F. 1960. Function of auditory cortex of cat in frequency discrimination. J. Neurophysiol. 23: 321-334.

1997. Associative learning. Int. Rev. Neurobiol. 41: 151-189.

Wakita, M. 1996. Recovery of function after neonatal ablation of the auditory cortex in rats (Rattus norvegicus). Behav. Brain Res. 78: 201-209.

Weinberger, N.M., R. Javid, and B. Lepan. 1993. Long-term retention of learning-induced receptive-field plasticity in the auditory cortex. Proc. Natl. Acad. Sci. 90: 2394-2398.

Wetzel, W., T. Wagner, F.W. Ohl, and H. Scheich. 1998. Categorical discrimination of direction in frequency-modulated tones by Mongolian gerbils. Behav. Brain Res. 91: 29-39.

Whitfield, I.C. 1969. Response of the auditory nervous system to simple time-dependent acoustic stimuli. Annu. N.Y. Acad. Sci. 156: 671-677.

Winter, P., D. Ploog, and J. Latta. 1966. Vocal repertoire of the squirrel monkey (Saimiri sciureus). Exp. Brain. Res. 1: 359-384.

Yapa, W.B. 1994. "Social behavior of the Mongolian gerbil Meriones unguiculatus, with special reference to acoustic communication." Ph.D. thesis, Ludwig-Maximilians University, Munich, Germany.

Zuschratter, W., P. Gass, T. Herdegen, and H. Scheich. 1995. Comparison of frequency-specific c-Fos expression and Fluoro-2-deoxyglucose uptake in auditory cortex of gerbils (Meriones unguiculatus). Eur. J. Neurosci. 7: 1614-1626.

Received July 7, 1998; accepted in revised form April 5, 1999.

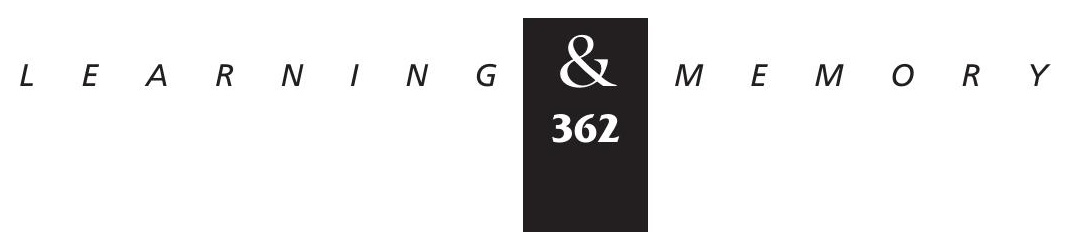




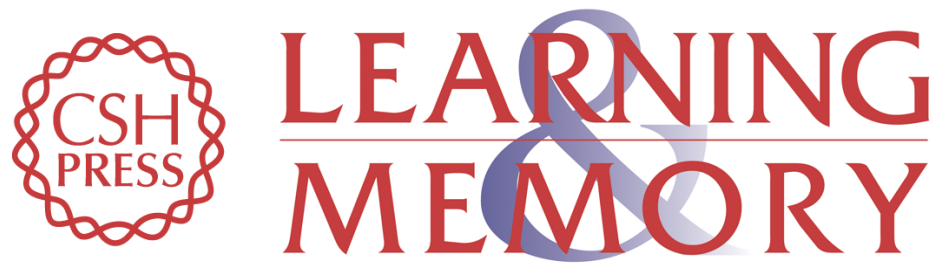

\section{Bilateral Ablation of Auditory Cortex in Mongolian Gerbil Affects Discrimination of Frequency Modulated Tones but not of Pure Tones}

Frank W. Ohl, Wolfram Wetzel, Thomas Wagner, et al.

Learn. Mem. 1999, 6:

Access the most recent version at doi:10.1101//m.6.4.347

References This article cites 76 articles, 5 of which can be accessed free at: http://learnmem.cshlp.org/content/6/4/347.full.html\#ref-list-1

License

Email Alerting

Receive free email alerts when new articles cite this article - sign up in the box at the Service top right corner of the article or click here. 